\title{
Guidance and Counseling Services in Schools of Bangladesh: An Exploratory Study
}

\author{
Saira Hossain ${ }^{1}$, Rajib Ahmed Faisal ${ }^{2}$ \\ ${ }^{1}$ Lecturer (Part-time), Institute of Education and Research (IER), Department of Educational Psychology and Guidance \\ University of Dhaka, Dhaka 1000, Bangladesh \\ ${ }^{2}$ Researcher, Institute of Education and Research (IER), University of Dhaka, Dhaka 1000, Bangladesh
}

\begin{abstract}
The study aims to give an overview of available guidance and counseling services in schools of Bangladesh. The study was qualitative in nature. As the underlying motivation of the study was to gain insights about the nature of existing situation of counseling services in schools of Bangladesh, hence the authors gathered information from all categories of school available within the country. A total of 10 categories of schools were selected. Two schools from each category were selected purposively on the basis of accessibility and availability of the school administrator, teachers and students for detailed interviews. A semi-structured interview schedule was used to collect data from school administrators, teachers and students. School documents like student profile, curriculum, syllabus, event records as well as administrative and academic service records were also surveyed to get an in-depth understanding about the available counseling services in the respected schools. It is found that there is a lack of formal program for guidance and counseling. Some sort of service is provided to students but those are not planned, organized and holistic. Further, those are not readily intent for counseling purpose. Moreover, schools did not have any trained personal, solely responsible for such services.
\end{abstract}

Keywords: Guidance, Counseling

\section{Introduction}

*Tanisha, A 14 years old student from a renowned English medium school in Dhaka, Bangladesh; jumped off the fifth floor of the school building and expired on the spot. According to the school authorities the student was caught by a teacher while copying in the examination. The teacher then seized answer script and took him to the examination controller's room. When the school authorities were about to inform guardian, than the student sought time for going to fresh-room and ran straight to the fifth floor and jumped off [1]

..Konika, 16 years old school going student, ever smiling, full of life, leading what we called a perfect life with perfect family, jumps off the terrace of her house \& left this world forever. Nobody knows the reason behind that but irony is that in this world nothing is absolute, nothing is perfect. However, it is predicted that the student might not handle the pressure of upcoming exams. [2]

*Shoumen, 14, a student of class IX; mercilessly beaten and stabbed by a group of students of from another school of the same age. It is said that affair with a girl was the reason behind the conflict [3].

*Ratna, another student committed suicide at own residence in the city on $14^{\text {th }}$ April, 2010, as the parents did not take her out to Pahela Baishakh (Bengali New Years' Day)Program [4]. .................. and the list is too long to complete within this short context. These kinds of incidents have become very frequent in the daily newspapers of the country. In fact Juvenile delinquency like suicide, vandalism, peer bullying, absenteeism, among school going children is rapidly increasing day by day. If this is to happen, if the education system is failed to make the students understand the value of life, to stop the moral degradation of teenagers, then what's the contribution of education to our life? In Bangladesh, today education sector is one of the prime focuses of development. Lots of projects have launched, methods have taken, latest technologies and innovations are introduced to improve the quality of our schools, to enhance the quality of the education system. But in spite of all efforts we failed to meet the needs of changing pattern of socioeconomic, socio-educational and socio-cultural systems - we failed to cope with the changing nature of human behavior and a person's adjustment with his family, community and society; as a result we failed to stop these brutal incidents. In fact in a recent study, $22 \%$ of urban secondary school students were found to suffer from at least any one kind of emotional and behavioral adjustment problems or at risk of having such problems [5]. To counter the situation and to create a secure and healthy environment in school the government of Bangladesh places the need of effective counseling program in our schools [6]. Hence, it is timely to introduce the concept of counseling into our education system as well as from the early school level. The purpose of this study is to give an overview of available guidance and counseling services in schools of Bangladesh.

"Over the last few years there has been a huge growth of interest in the field of guidance and counseling. This has manifested itself in a number of areas: in health care, in family, in the work place and of course in the schools" [7]. The word 'guidance' and 'counseling' often used interchangebly though there remained differences between the two [8]. To be more specific "Guidance is a term broader than counseling and which includes counseling as one of its service” [8]. According to UNESCO (2000), "Guidance can be defined as a process, developmental in nature, by which an individual is assisted to understand, accept and use his/her abilities, aptitudes and interests and attitudinal patterns in relation to his/her aspirations"[9]. On the otherhand, Burks and Stefflre (1979) defind counseling in McLeod “ as a professional relationship between a trained counsellor and a 
client...It is designes to help clients to understand and clarify their views of their lifespace and to learn to resach their sel determined goals through meaningful, well informed choices and through resolution of problems of an emotional or interpersonal nature [10].”

Both guidanace and counseling have three major compnents. Such as: Educational, Vocational and Personal-Social [9].

In order to help in the holistic development of the students; to prepare them for best suited career and for challenges of this ever changing world, to make him well adjuted to the personal, social and emotional trajectories, proper guidance and counselling services are indispensable in schools [7][9].

\section{Methodology}

The study was qualitative in nature. As the underlying motivation of the study was to gain insights about the nature of existing situation of counseling services in schools of Bangladesh, hence the authors gathered information from all categories of school available in the country. A total of 10 categories of schools were selected. Two schools from each category were selected purposively on the basis of accessibility and availability of the school administrator, teachers and students for detailed interviews. The categories of schools comprising government primary and secondary, non-government primary and secondary, cadet, technical and vocational, English medium, non-formal schools, Madrasahs (Religious school) and Bangladesh Krira Shikkha Pratisthan [BKSP] (Bangladesh Academy of Sports Education). The distribution of sample schools and respondents is given below in table 1:

Table 1: Distribution of Sample

\begin{tabular}{|c|c|c|c|c|c|}
\hline \multirow{2}{*}{\multicolumn{3}{|c|}{ Category of Institutions }} & \multicolumn{3}{|c|}{$\begin{array}{c}\text { Number of } \\
\text { sample/participants }\end{array}$} \\
\hline & & & 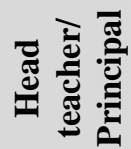 & 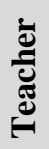 & 节 \\
\hline \multirow{2}{*}{ 胥 } & & Government & 1 & 2 & 2 \\
\hline & & Non-government & 1 & 2 & 2 \\
\hline \multirow{2}{*}{ 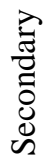 } & & Government & 1 & 2 & 2 \\
\hline & & Non-government & 1 & 2 & 2 \\
\hline \multicolumn{3}{|c|}{ Cadet School and College } & 1 & 2 & 2 \\
\hline & & BKSP & 1 & 2 & 2 \\
\hline \multicolumn{3}{|c|}{ Non-formal school } & 2 & 2 & 2 \\
\hline \multirow{2}{*}{\multicolumn{2}{|c|}{ 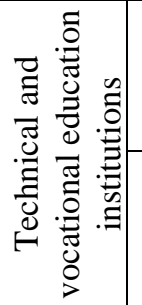 }} & Government & 1 & 2 & 2 \\
\hline & & Non-government & 1 & 2 & 2 \\
\hline \multicolumn{3}{|c|}{ Total number of participants } & 10 & 18 & 18 \\
\hline
\end{tabular}

A semi-structured interview schedule was used to collect data from school administrators, teachers and students. School documents like student profile, curriculum, syllabus, event records as well as administrative and academic service records were also surveyed to get an in-depth understanding about the available counseling services in the respected schools. Thematic analysis technique was used to analyze the data. Here the guidance services found in previous literature [9], [8] were termed as themes. Data were represented under each theme in a narrative form. The selected themes were given below table 2 for reader's perusal.

Table 2: Guidance and Counseling Service

\begin{tabular}{|l|l|}
\hline S.L. & \multicolumn{1}{|c|}{ Theme } \\
\hline 1. & The Orientation Service \\
\hline 2. & The Information Service \\
\hline 3. & Counseling \\
\hline 4. & The Career and Placement Service \\
\hline 5. & The Referral Service \\
\hline 6. & The Remedial Service \\
\hline 7. & The Follow-up Service \\
\hline 8. & The Evaluation Service \\
\hline
\end{tabular}

\section{Findings}

\subsection{The Orientation Service}

The new students who get admitted into a school are come from heterogeneous background. Some come from village, some from different town. There are some from high socioeconomic background some from low; some come from happy homes and some from unhappy homes. Also they come from other schools with particular characteristics of their own. "An adequate orientation service can provide for articulation and continuity from one school to another; from one set to other" [8] through orientation programs new students and their parents can get information about the school, understand its rules, regulations and available facilities. Hence, the novice student can "identify himself with the school environment with minimum mistakes and worry and a maximum of success and satisfaction” [8].

In almost all the sampled institutions, as a part of the orientation service printed materials in the form of leaflet containing school profile, admission information, staff members etc. are provided for new students and their parents. Orientation Day observance is another part of orientation service. The study did not find any event like 'Orientation Day' in state funded primary and secondary schools, and Madrasas (Religious School). However, private primary and secondary schools offer for Orientation Day program to the students with parents to get acquainted with their rules and regulation. A head teacher said, "we organize an orientation day to new pupil and their parents to let them know about our school policies, traditions, rules of conduct, organization of the student body, extra-curricular activities and to give a feeling of at-home”. Orientation to school is one of the basic functions of guidance service in cadet schools and colleges. According to a principal of a cadet college "The individual who comes to the school has many adjustments to make, as he is entering a new and different environment. The orientation program is a way to 
welcome the new comers and help them develop an attitude of interest in schools. In the cadet schools the orientation programs occurred in a big context all the parents are invited with the novice cadets, the principal greets the entrants, they are acquainted with the customs, rulesregulations, physical surroundings, teachers and senior cadets of the of the academy". In English medium schools orientation services have manifold features they not only organize event like orientation day but also have very sophisticated and organized information desk at the entrance. Some provide handbook which include welcome note from school administrator, information regarding course, fees, stipends, scholarship, available facilities etc. Nevertheless, the non-formal school did not provide any aforementioned orientation services. On non-formal school teacher mentioned, "We have some promotional items like leaflet, brochures for donors and stakeholder. However, those were not intent to give any orientation to parents and students."

\subsection{The Information Service}

Information service can consist of different types of information. Such as: a) Student Information which includes record of students' progress in terms of academics, health, extra-curricular activities, level of aspirations, personal traits, interest, aptitude etc. b) Educational Information which includes prospectus from different relevant institutions, book, pamphlet, scholarship, student loan offered by different external government and nongovernment bodies, leaflet or hand books on study skill etc. c) Personal-Social skill which includes illustrated material, handbooks, leaflet, book let on self-understanding, health and hygiene, adolescent reproductive health, sex education etc.[8].

In almost all the school there is a student information service which includes information only about academic progress throughout the year. However it depicted a scattered picture about a student. Only in cadet school and in BKSP, a somewhat holistic student portfolio is maintained which gave a clear view to know an individual student's traits, interest and progress.

Educational information service is available in every private school. However, in govt. schools this service is not found organized and updated. A secondary school teacher stated, "There is a student information service for students to let them know about scholarships offered by the government or ministry of education or social agencies, public schools provide some educational information." A teacher of English medium school added, "we provide information on different national and international sport and extra-curricular events like Math and Language Olympiad, Quiz, education fair, essay competition etc. Moreover, we organize workshop on different academic skill and exam preparation." Except nonformal school and Madrasahs (Religious school) all categories of schools have student and education information services. However, the study did not find any personal-social information service provided for the students in schools except the cadet school and college and the BKSP. Health guidance is very much emphasized. Different types of physical checkup are done, lessons on cleanliness, healthy living habits is given on a regular basis over there. In fact the respondents could not give any clear understanding about the concept. Nevertheless, it is notable from the study that in most of the institutions information service is not suitably compiled, maintained and readily available always.

\subsection{Counseling}

Counseling is one of the most prominent components of guidance and counseling services in school. This service intends to assist students in achieving optimum educational, vocational, personal-social-emotional development and adjustment [8]. However, the study found that there is no trained counselor to meet the individual needs of the students in the sampled schools. In every govt. primary schools there is a SMC (School Management Committee) for the welfare and good governance of the school and students but they do not bother about the counseling need of the children. The Situation is merely same in high schools though learners at this level are perhaps in greater counseling need than any other period in their educational experience. As in their physical and psychological development they find their urges and derives unleashed in a most disturbing manner [5]. Moreover, during adolescence period several physical and emotional changes occur due to the hormonal change. Teenagers are confused about those changes, their social role, relationship to other sex, attitudes of others towards them, choice of subject, careers as well as their future. In fact they might have difficulties to adjust with other peers as they all come from different socio-economic background. But in public high school there is no such professional personnel to whom they could share their feelings, clear doubts and to understand what he can do and what he should do. One Head teacher mentioned, "As the head teacher I am mainly responsible for the overall counseling of students which I think is not accurate at all, as my position demands to control everything but counseling is not controlling”. Thus it seems in these schools counseling is limited to imposing some hard and fast rules to students irrespective of their needs.

BKSP's counseling situation is comparatively quite good, as a sport psychologist is assigned to serve as guidance personnel. His main focus is on the students' nonacademic performance, his mental peace and balance. A student from BKSP said, "The guidance personnel motivated us, solved our performance related and other personal or emotional quarries." The sports psychologist have data on each students \& according to the data he tries to synchronize his experience in order to produce highly caliber \& mentally strong sports performer.

As we know in cadet schools discipline is the first and last thing and here counseling means to make the students disciplined in any way. Though the services provided here is quite better than overall existing situation. Every senior cadet is formally assigned to guide an immediate junior cadet and is responsible for all his deeds. There is a duty sir for every 'house' (hostels for cadets are called 'house' there are 3 house in every cadet college except Faujderhat cadet college) in every cadet schools who is assign to solve students' quarries outside the classroom. The duty sir is not any trained counselor, he is just a subject teacher and not permanent for a particular 'house'. Everyday different 
teachers are assigned for different 'houses' as duty sir. As the duty sir is basically a teacher he mainly solved student's academic problems and not bother for their nonacademic or personal quarries.

Counseling in the religious schools is found as nothing but dictating. As the students are come from poor family and bound to stay there, the authorities strictly imposed several rules and customs onto the students in the name of Islam and cruelly punished them if they refused to follow. According to a madrasah teacher, "the best way of guidance is to punish students e.g. to whip the students, tie them to the door like a domestic animal, to lock them in a dark isolated room, keep them hungry day after day.”

There is an administrative supervisor in every school who is responsible for the overall counseling of the students. He also plays the role of student advisor but he only manages time to solve students' academic problem e.g. course selection, attendance, advance leave, sick leave, scholarship etc. But he doesn't bother about their non-academic problem \& the reasons behind their academic problem. For example if a student is inattentive in his classes his duty is to warn him \& explain him the school rule as a consequence of his this type of conduct, he never concerned with why he is inattentive? Does he have any family problem? Does he have any peer conflict? Does he have something special to share? Does he have some special needs? Does he is in confusion? Does he is in depression? Etc. As they are not professionally trained for counseling and they have other administrative responsibilities they can't manage to focus on the individual need of students.

\subsection{Career and Placement Service}

Career and Placement service includes information about different occupation, help students to choose best suited course, extra-curricular activities, getting part-time job, getting different skill based training, to place himself on the right track of career path [8].

It is found in the study that apart from Non-formal schools there is no formal provision of helping students to get parttime job or to place them into other forms of apprenticeship. Non-formal schools provide career counseling and placement services by running different income generating programs, skill-based training, micro-credit projects and follow up services. One non-formal school teacher mentioned, "We counsel students for a particular vocation according to his interest, capability and need." Another teacher added, "There is a scanty of various the options. The career options provided in our school are grossly limited within the project proposal approved by the donor organization; we can't offer other options beyond the proposed activities of the project.

Career counseling is an essential part for the building of student's future. High school students are full of life and sometimes difficult to control, vocational activities can help in developing self-discipline among student. However, both in public and private school there is hardly such opportunity for students to help them making choice of career or choosing professional course. A teacher from cadet school and college stated, "On many occasions personnel from different defense force (air, navy, arms) come to the academy and provide information about career in that field. Such service partially fulfills vocational guiding needs though it is confined only within army background related job description". On the other hand, the technical and vocation education is directly allied with the career but students are mainly prepared for a particular vocation but there is nothing like vocational guidance. According to the principles adopted by the National Vocational Guidance Association, "Vocational guidance is the process of assisting the individual to choose an occupation, prepare for it, enter upon and progress in it." But there is no one in these schools to guide the individual about his own strength and weakness, to answer "what is the best he fitted for?" It was found that technical and vocational schools have only trainers who just trained the student without understanding that does the student capable enough for the training? If he is not then what are the other options open for him. In fact after the completion of the training program from the schools there is no placement and follow up service to help the student if necessary. In a developing country like ours, opportunities are limited and we limit them more by not adopting the vocation best suited to follow as there is no proper career counseling service.

\subsection{The Referral Service}

Referral service intended to channel up students who need special care into specialized institutions which can better help them [8]. The study found that in formal school there is no referral service for students who need more specialized treatment. One non formal school teacher said, "we have very limited referral service for students who have one or multiple types of impairment such as physic, visual or hearing." However, such referral services are confined only within some visible kinds of disabilities. Nevertheless, there might many hidden disabilities, internalized problems like depression, anxiety, stress, social phobia etc. Such problem easily remained disguise due to lack of proper counseling and referral service.

\subsection{The Remedial Service}

Remedial services intend to locate and mend problems faced by an individual student in schools. As a part of this service school take the endeavor to provide appropriate training, therapy, counseling as a remedy of problems [8]. No school is found to be capable of remedial service. In facts no remedy is given to students who are in need of; punishment, complain to parents, give T.C (Transfer Certificate) on extreme cases are the only remedies to control the challenging behavior or mend problems of the students.

According to the head teacher of a government secondary school, "in our classrooms teacher-student ratio is not compatible; teachers can hardly manage large number of students \& run the teaching-learning practices. In these situation they are not able to locate the pupil who is not responding, who is not working up to his ability, who is hyperactive, who is shy, who is aggressive, who feels lost \& who is inattentive". Another head teacher stated, "Teachers are not trained to identify pupil with problems arising from 
personal handicaps. They don't have adequate knowledge of child psychology and developmental milestones of children, even most of them don't bother to apply their training experience from P.T.I (Primary Training Institute) in the classroom". According to the teachers, they report to the head teacher or to the parents for any undisciplined act of the child or any significant problem he is encountering but they don't give any remedial service usually. According to the participant, some students might have defects in speech, hearing, reading and study habit but there is no remedial service to enable them to overcome these handicaps. For disruptive behavior e.g. fighting with peer, stealing, copying etc. schools provide physical or mental punishment instead of strategically handle or give remedial guidance to the individual.

According to the teachers from cadet school, sometimes extreme issues happen among cadets e.g. frustration, homosexuality, impulsiveness or other teenage oriented problem \& if the authority come to know these then it is carefully handled with the involvement of parents \& counselor on special cases. A student from cadet school stated that “naturally cadets don't involve in peer conflicts as they know the punishment is very strict from the authority for these kinds of deeds. Sometimes conflicts happen between two classes then it is informally managed by senior cadets, suppose there is conflict between the students of class VI \& VII then it is solved by the cadets of class xii. In fact senior cadets provide informal guidance to the junior cadets on some occasion if they are in need of".

\subsection{The Follow-up Service}

Follow services intend to know whether students get benefitted and able to be well adjusted in post school life by the guidance and Counseling services provided in schools [8].

The study found that in cadet school and college and in BKSP there have some follow up services by means of which they can track the progress of their graduates. The cadet school teacher added, "We maintain track record of our graduates. However, this data is merely serves as our record. We hardly analyzed those to take any future endeavor for the assistance of students."

Other sample schools and Madrasah mentioned that they did not maintain any follow up of their graduate students. In this respect the situation of non formal school is quite better as they have follow up service. In fact they provide some incentives for their graduate who found to be on the optimal track of development. One non formal school teacher mentioned, "We give stipend to our primary graduates who get enrolled into the grade VI and continue their secondary education.”

\subsection{The Evaluation Service}

Evaluation service measures the efficacy of entire guidance and counseling program in school and provides directions for future plans and project. It also points out the strengths and weakness of the available services as well as ensures accountability of the programs [8]. As there is no formal and planned guidance and counseling program is not running in any schools. Hence, the study did not found any sort of evaluation service. However, in NGO school for the sake of impact study and measuring the program efficacy an evaluation is done but those were not solely focused on guidance and counseling. In English medium schools there remains a teacher evaluation system but not any evaluation of counseling services provided in schools.

\section{Discussions}

From the study of the sampled schools, it is found that there is lack of formal program for guidance and counseling. Some sort of service is provided to students but those are not planned, organized and holistic. Further, those are not readily intent for counseling purpose. Moreover, schools did not have any trained personal, solely responsible for such services.

There isn't any provision for individual counseling need of students. "Same size fits all" describe best the overall guidance and counseling situation of schools in Bangladesh though the need of counseling service for better adjustment in both primary and secondary level is well documented in previous literature [7]-[9]. As in primary schools, students entered into a new environment leaving behind the security of mother-child attachment. Further, in secondary school students are at transitional period from childhood to adulthood. They need counseling service to understand their emotions, clear their doubts and conflicts; they need someone to whom they can share the special experience and feeling of their life [9]. Though addressing proper guidance and counseling service many problems like absenteeism, delinquency, suicidal tendency, low achievement etc. could easily addressed, schools could not provide amend counseling service. Lack of resources, incompatible teacher student ratio, lack of proper supervision and accountability might be a plausible reason behind poor guidance and counseling service [11].

\section{Conclusion}

In a nutshell, the services rendered by the teachers in Bangladeshi schools are generally preparatory steps to guidance and were not actually the process of guidance which would help the pupil to solve their problems. It is high time we should give concern to this emerging issue as our education system is suffering from a lot of problems. Being a developing country we have lots of constraints, lack of resources, high drop-out rate, and low teaching-learning quality moreover increasing delinquency among school children all refers to a single need i.e. appropriate, well organized and effective guidance and counseling program in our school. Further, in today's world education does not confined within a cubical classroom, good or bad now the world is a classroom and there exist unfamiliar complexities and challenges to address. Thus separating education from guidance and counseling, it is evident that this approach is not going to work today. So top level commitment and effort should be given to implement guidance services in schools to make it more effective and a vehicle for sustainable development. 


\section{Recommendations}

It is evident that guidance situation in Bangladeshi schools is not satisfactory enough to provide emerging needs. To develop the guidance situation some recommendations are given below:

- First of all it is important to raise awareness towards guidance needs in schools among teachers, parents, educators, administrators and community through seminars, posters, film, school trip, panel discussion, FGD, puppet show, print \& electronic media.

- There should be national level guideline about school guidance and counseling.

- It is essential to introduce a guidance oriented curriculum in both primary and secondary level to stimulate the interest, appreciation and co-operation of those who participate.

- There should be a saying about guidance in the curriculum so that the teachers will not consider it as an extra teaching assignment.

- There should be time aside for guidance services in the curriculum as well as in school program.

- Guidance and counseling course should be included in teachers' training program.

- There should be an opportunity of in-service training on guidance and counseling not only for teacher but also for educator, administrator, state and district level personnel and others.

- Diploma courses on guidance and counseling should be introduced to create new professionals in this field.

- Position of fulltime professional guidance personnel or school counselor or educational psychologist should be established in each primary and secondary educational institution all over the country.

- In every school there should be guidance and counseling department under which different guidance services e, g. orientation to the school, educational and vocational guidance, students' information service, remedial, referral and follow up services are planned, organized and supervised. This department can provide guidance training for teacher of that school, parental guidance to parents, arrange program to raise awareness about the importance of guidance in community.

- School should provide enough space for the office and clerical assistance to maintain the various activities of the guidance and counseling department.

- Schools having active guidance and counseling department should be awarded by the government. Fund can be given on the basis of effectiveness of guidance program of a school.

- National guidance and counseling association should be established under ministry of education. Having branches in each education board to provide and supervise guidance services in regional school.

- Guidance and counseling association can organize group guidance program for adolescence on substantial topics.

- Education ministry should allocate budget for the training of guidance personnel and improvement of the overall guidance situation in all educational institutions.

- The government should provide guidance material e.g. book/ brochures containing information on scholarship and loans, occupational files and manuals, mental health material, tape recorders for speech articulation, illustrative materials suppose films, filmstrips, posters, charts, different play instrument to run playful activities (especially in primary school) and various aids \& create opportunities for a vocational activities in school.

- School should develop adequate facilities for keeping records in order to use frequently to remedial services to pupil.

- There should be a research service intended to examine both the personnel in the school guidance program and the techniques of guidance used by them so as to discover their strong and weak points.

- The government should provide fund for creating several guidance organization and encouraging fundamental research in the related field.

\section{References}

[1] The Daily Prothom Alo. পরীক্যায় थারাभ করায় আম্মহন্না [Commits suicide due to fail in the exam]. The Daily Prothom Alo, Retrieved on July 20, 2012 from http:// www.prothom-alo.com, 2006.

[2] The Daily Prothom Alo . স্কুল ছাত্রীর আঞহন্না [ Girls student Commits suicide]. The Daily Prothom Alo, Retrieved on January 20, 2013 from http:// www.prothom-alo.com, 2009.

[3] Barua, D. Juvenile Crimes on the Rise. The Daily Star, Retrieved on May 20, 2011 from http://www.thedailystar.net/newDesign/newsdetails.php?nid=132389, 2010

[4] The Daily Star. Viqarunnisa student commits suicide. The Daily Star, Retrieved on October 1, 2013 from http://ep.thedailystar.net/index.php?opt=view\&page=5\& date $=2010-04-16,2010$.

[5] Hossain, S. A Study of Determining the Relationship between Academic Achievement and Problem Behavior of Urban Secondary School Students in Bangladesh. The International Journal of Social Science, 8(1), pp. 001-010, ISSN: 2305-4557 http://www.tijoss.com/8thVolume.html, 2013.

[6] National Education Policy. Ministry of Education. Retrieved on October 2, 2013 from http://www.moedu.gov.bd/, 2010.

[7] Bor, R., Ebner-Landy, J., Gill, S., \& Brace, C. Counselling in Schools. SAGE Publications Ltd., pp. 01, 2002.

[8] Kochhar,S.K. Educational and Vocational Guidance in Secondary Schools. Sterling Publishers Private Ltd: India, pp 15-100, 1996

[9] UNESCO (2000). Guidance (Module I). Paris: Agzi Communication.

[10] McLeod, J. An Introduction to Counseling. Open University Press. UK, pp.7, 2003

[11] Mapfumo, J., \& Nkoma, E. The State of Guidance and Counselling Programmes in High Schools in Manicaland, Zimbabwe. International Journal of Scientific Research in Education, 6(2), 100-116. Retrieved from http://www.ijsre.com, 2013. 


\section{Author Profile}

Saira Hossain is now working as a Lecturer (Part-time) at Department of Educational Psychology and Guidance, Institute of Education and Research, University of Dhaka. Her area of research interests are social and emotional adjustment of students in school, student's voice, school environment, inclusion in education etc.

Rajib Ahmed Faisal is currently working as a Researcher at the Institute of Education and Research (IER) of University Dhaka. He is doing his MPhil in Education at the University of Dhaka. His area of research interests are ELT, curriculum, inclusive education, psychology, community development etc. 